\title{
Elemental Detection of Zinc in Ayurvedic Drug (Jasad Bhasma) by Radioisotope induced Energy Dispersive X-ray Fluorescence (EDXRF) Technique
}

\section{Daisy Joseph ${ }^{\star}$}

Nuclear Physics Division, BARC, Trombay, Mumbai, India

\section{Article Info}

\section{*Corresponding author:}

Daisy Joseph

Nuclear Physics Division

Bhabha Atomic Research Centre

Trombay

Mumbai-400085

India

Email: djoseph@barc.gov.in

\section{Received: May 17, 2018 \\ Accepted: May 30, 2018 \\ Published: June 6, 2018}

Citation: Joseph D. Elemental Detection of Zinc in Ayurvedic Drug (Jasad Bhasma) by Radioisotope induced Energy Dispersive X-ray Fluorescence (EDXRF) Technique. Madridge J Anal Sci Instrum. 2018; 3(1): 73-76.

doi: $10.18689 /$ mjai-1000114

Copyright: ๑ 2018 The Author(s). This work is licensed under a Creative Commons Attribution 4.0 International License, which permits unrestricted use, distribution, and reproduction in any medium, provided the original work is properly cited.

Published by Madridge Publishers

\begin{abstract}
Many minerals have been successfully used in Ayurvedic therapy. These minerals are processed appropriately prior to its use. Such products may also be used in combination with herbs. These products are often a blend of trace elements. The various procedures are mentioned in Ayurvedic text for the manufacture of the same preparation. In the present study nine preparations of Jasad Bhasma along with zinc oxide were analyzed for their trace element composition using $A \mathrm{~m}^{241}$ radioisotope source induced $\mathrm{X}$-ray Fluorescence. Jasad Bhasma preparations prepared using different processes showed significant levels of $\mathrm{Zn}$ (22\% to $48 \%$ respectively. The other trace elements were also detected at significant level in these preparations. It is concluded that a uniform procedure need to be adopted to bring uniformity in the quality of Ayurvedic drugs.
\end{abstract}

Keywords: ZincZinc; Jasad Bhasm; Ayurveda; EDXRF; Radioisotope.

\section{Introduction}

Jasad Bhasma is the Ayurvedic preparation containing zinc used to treat several diseases [1]. Zinc is an essential element whose relevance is accepted by the modern medicine. Popularity of "Ayurvedic medicine" in society, technological advances in manufacturing process and the encouragement from Government has resulted in Indian market being flooded by Ayurvedic drugs [2,3,4]. Quality control standards for the commercially available preparation are not precisely laid down. The quality control tests mentioned in Ayurveda are mostly subjective. The pharmacopoeia standards for Ayurvedic formulation do mention about the total zinc content in the Jasad Bhasma but the procedure to determine the zinc content is not specified $[5,6]$. Hence it becomes essential to validate the products and develop the quality control tests using modern technology [7]. We present here sensitive, non-destructive and rapid technique (Radioisotope Induced Energy Dispersive X-ray Fluorescence EDXRF) to obtain elemental composition of the Ayurvedic preparation Jasad Bhasma. (Fig1). 


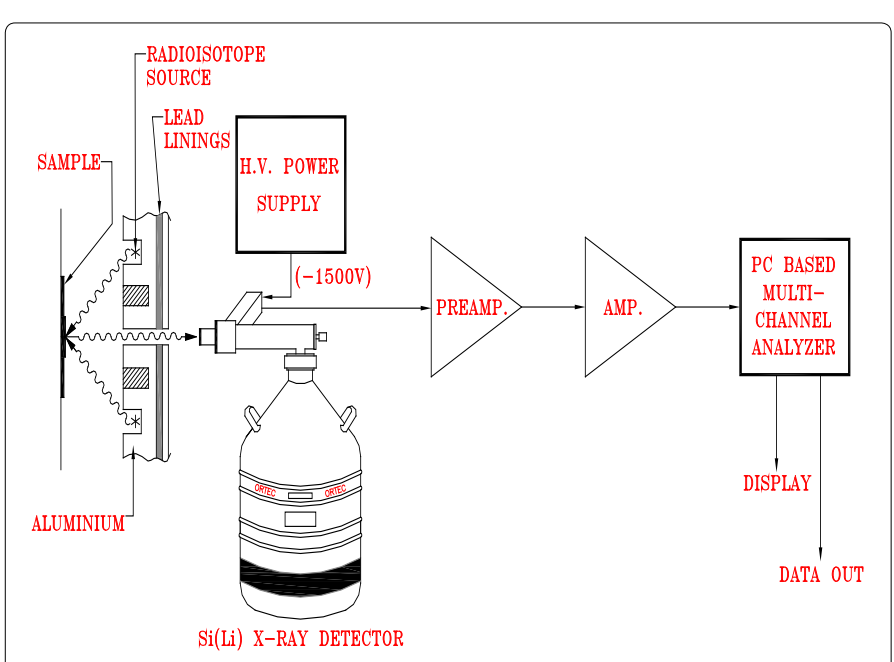

EXPERIMENTAL SET UP FOR

ENERGY DISPERSIVE X-RAY FLUORESCENCE (EDXRF)

Figure 1. Experimental set up of EDXRF

A reverse bias of $800 \mathrm{~V}$ was applied across the semiconductor junction of $\mathrm{Si}$ (Li) detector and the resolution of the detector was $150 \mathrm{eV}$ at $5.9 \mathrm{keV}$. The samples were powdered finely and mixed with cellulose as a binding material to make self-supporting pellets weighing $300 \mathrm{mg}$. The samples were then placed in front of an XRF spectrometer. For the excitation of the samples, Am 241 radioactive source and $\mathrm{Cd} 109$ were employed in annular geometry to prevent the direct exposure of the excitation source to the detector and minimize backscatter interference. The Am 241 emits $60 \mathrm{KeV}$ gamma ray and the $\mathrm{Cd} 109$ emits $22.2 \mathrm{KeV} \mathrm{Ag} \mathrm{K} \mathrm{X-rays.} \mathrm{The}$ $X$-ray spectra were recorded for a counting time of 2000 seconds and stored in a PC based multi-channel analyzer for further offline analysis.

\section{Sample Preparation and Methodology}

$500 \mathrm{gm}$ of zinc granules were weighed on two pan balance (Libra). Kadhai (iron utensil) was placed on a gas burner. Zinc granules were heated till they melted. The molten mass was poured in a container containing milk (200 ml). This exercise was repeated 21 times.

\section{Para-Gnadhak Marit Bhasma}

$100 \mathrm{gm}$ of Shudha Jasad was weighed on two pan balance. Kadhai was placed on a gas burner. Weighed Shudh Jasad was placed in it and heated intensely till it melted. The molten mass was triturated thoroughly with mercury $(100 \mathrm{~g})$ in Khalva Yantra. Lemon juice $(100 \mathrm{ml})$ was added and mixed till a uniform mass was obtained. The excess of lemon juice was filtered off. The product was labeled as Y. To the residue 100 grams of sulfur was added. The mass was triturated thoroughly for two hours to get homogenic mass. It was subjected to Gajaputt to obtain bhasma.

\section{Vanaspati Marit Bhasma}

$100 \mathrm{gm}$ of Shudha Jasad was weighed on two-pan balance. Kadhai was placed on gas burner. Weighed Shudha Jasad was placed in it and heated intensely. When it melted, powdered Achyranthus aspera was added (about $5 \mathrm{gm}$ ) and stirred constantly. The process continued till, all the powder of the plant was utilized. The Kadhai was covered with stainless steel lid and the heating continued overnight i.e. for about twelve hours. Next day material was allowed to cool to the room temperature. Yield was measured on a two pan balance at the end of the process and was found to be 160 $\mathrm{gm}$. The fine powder obtained at the end of the process was divided into two parts. One was labeled as B1 and was used subsequently in various experiments as a test Formulation B1. The remaining half was subjected to the third step of Mardan and Bhavan.

Puttan: In an earthen pot (Sharav), the intermediate product was placed. The other earthen pot was then placed on the top of the first in an inverted position. Care was taken to align the edges of both the vessels properly. The thin layer of cloth dipped in a wet multani mitti was tied. Five to six layers of multani mitti were applied over it. All the mud layers were allowed to dry. In the pit $(75 \mathrm{~cm} \times 75 \mathrm{~cm} \times 75 \mathrm{~cm})$ dried cow dung cakes were arranged to cover half of the pit. The tightly closed vessel containing the test material was placed on top of these cow dung cakes. Remaining half of the pit was covered again with cow dung. Fire was set and heating continued till it extinguished on its own. The utensil was removed on the next day when the room temperature was attained. It took nearly 24 hours. In addition, it was decided to compare these formulations with the Jasad bhasmas of different companies available in the market. Zinc oxide and Zinc powder manufactured by M/s s.d. fine chemicals, Mumbai was also used for comparison. Thus, in all, analysis of 10 formulations was carried out. The list is given below:

1. Paragandhak -Marit Jasad Bhasma -- A

2. Vanaspati Marit Jasad bhasma (Intermediate) -- B1

3. Vanaspati Marrit Jasad bhasma (Final) -- B2

4. Jasad Bhasma from Zandu Pharmaceuticals Ltd, Mumbai -- $C$

5. (Sharangdhar Samhita Madhya Khanda)\#

6. Jasad bhasma form Baidynath Ayurved Bhavan, Nagpur -- D

7. (Ras Raj Sunder)\#

8. Jasad bhasma from Dhootpapehswar Ltd, Panvel -- E

9. (Bharat Bhehhyjya Ratnavali)\#

10. Jasad bhasma, Manilal Lallubhai, Pune -- F

11. (Ayurved Sar Samgrah)\#

12. Zinc oxide, s.d. fine-chemicals, Mumbai -- G

13. Zinc Powder -- $X$

14. Amalgam -- $Y$

\# As mentioned on the label.

Each of the above formulation was mixed with cellulose (50\%) and homogenized self supporting pallets were prepared on hydraulic press for EDXRF analysis. The analysis consisted of 
$\mathrm{Si}(\mathrm{Li})$ detector of resolution $170 \mathrm{eV}$ at 5.9 Mn Ka X-ray amplifier and PC based MCA. Each sample was analyzed using Am 241 Radioisotope source for a counting time of 2000 Seconds.

\section{Results and Discussion}

Table 1 gives the concentration of trace elements in various formulations. It is seen that in pure zinc samples the Zinc concentration is $64 \%$. After maran the zinc content is reduced to $22 \%$ and finally after Gajjaputta the zinc content become $34 \%$. In the second procedure the amalgam which contains $15 \%$ zinc, $17.8 \%$ Mercury after subjecting to Gajjaputta zinc content went up to $48 \%$ and no mercury at all. It is likely that at this temperature, vaporization of mercury or sulfur takes place but freed zinc or zinc sulfide gets converted to zinc oxide. The sublimation point of zinc oxide is higher than the heat generated in Gajjaputta and hence the process ultimately delivers the product of desired nature, in powdered form. However, this test was extremely useful to detect the elements like mercury, phosphorous, iron, cobalt, nickel, tin and lead which were present in ppm quantity and would have been missed otherwise.

In Formulation A prepared by Para-Gandhak marit method, mercury and sulfur were found to be absent indicating complete sublimation of these two elements. This proves that the process of puttan removes them. However, a significant concentration of phosphorous, iron, cobalt, nickel, tin and lead ranging in concentration from 220, 1905, 983, 139, 2505 and 883 ppm respectively were detected. Of these, iron was expected as zinc granules were melted in iron utensil. The sources of other elements could be from the raw materials or those added from the accessories used during the process.

In Formulation B2 iron, tin and calcium was found in high concentration. These were absent in Formulation B1. It should be noted that the intermediary product after maran was processed for Bhavana in metal stone. One of the plants used for giving Bhavana is Aloe vera, which is a rich source of calcium. Trituration using the metal stone and use of Aloe vera can explain the presence of iron and calcium. The presence of tin was seen in both, Formulation A and B2, but not in FormulationB1. The former two were subjected to puttan in an earthen sharav, which might be the source of tin. Formulation $\mathrm{F}$ also showed presence of tin and lead. As this was purchased from the market, comment cannot be made on the origin of these elements. However the light gray colour of this formulation may due to presence of lead.

\section{Conclusion}

Analysis of different Jasad bhasma obtained from the various sources indicated that its trace element content varies. The variation could be due to the different procedure of preparation. Jasad bhasma which is primarily a salt of zinc showed zinc content ranging from $15 \%$ to $55 \%$ indicating the non uniformity in the respect of its zinc content. The variation in the zinc content over such a wide range can in turn affect the quality of the product. Besides zinc the other trace element were also detected in significant in two preparations.
These other trace elements include lead and tin. Lead is considered as protoplasmic poison and can poise problems in therapy. Based on our study it can be concluded that various manufacturing outlined in Ayurvedic text results in variation in chemical composition of the Ayurvedic products to a significant level.

Table 1. EDXRF Pattern of formulation of Jasad Bhasma

\begin{tabular}{|l|l|l|l|l|l|l|l|l|l|l|}
\hline \multirow{2}{*}{ No } & Formulation & \multicolumn{7}{|l|}{ Concentration of various elements } \\
\cline { 3 - 12 } & & $\begin{array}{l}\text { P } \\
\text { PPM }\end{array}$ & $\begin{array}{l}\text { Ca } \\
\text { PPM }\end{array}$ & $\begin{array}{l}\text { Fe } \\
\text { PPM }\end{array}$ & $\begin{array}{l}\text { Co } \\
\text { PPM }\end{array}$ & $\begin{array}{l}\text { Ni } \\
\text { PPM }\end{array}$ & $\begin{array}{l}\text { Zn\% } \\
\text { PPB }\end{array}$ & $\begin{array}{l}\text { Pr\% } \\
\text { PPM }\end{array}$ & $\begin{array}{l}\text { Sn } \\
\text { PPM }\end{array}$ \\
\hline 1 & A & $220^{*}$ & ND & $1905^{*}$ & $983^{*}$ & $139^{*}$ & 48 & $883^{*}$ & ND & $2502^{*}$ \\
\hline 2 & B1 & ND & ND & ND & ND & ND & 22 & ND & ND & ND \\
\hline 3 & B2 & ND & $3369^{*}$ & $2227^{*}$ & ND & ND & 34 & ND & ND & $279^{*}$ \\
\hline 4 & C & ND & ND & ND & ND & ND & 54 & ND & ND & ND \\
\hline 5 & D & ND & ND & ND & ND & ND & 15 & ND & ND & ND \\
\hline 6 & E & ND & ND & ND & ND & ND & 23 & ND & ND & ND \\
\hline 7 & F & ND & ND & ND & ND & ND & 18 & $433^{*}$ & ND & $3350^{*}$ \\
\hline 8 & G & ND & ND & ND & ND & ND & 58 & ND & ND & ND \\
\hline 9 & X & ND & ND & ND & ND & ND & 64 & ND & ND & ND \\
\hline 10 & Y & ND & ND & ND & ND & ND & 15 & 2579 & 17.8 & 930 \\
\hline
\end{tabular}

*ppm - Parts per million ND- not detected

$\mathrm{P}$ - Phosphorous; Fe - Iron; Co- Cobalt; Ni - Nickel; Zn - Zinc: Sn- Tin; Pb-Lead; Hg- Mercury; Ca- Calcium

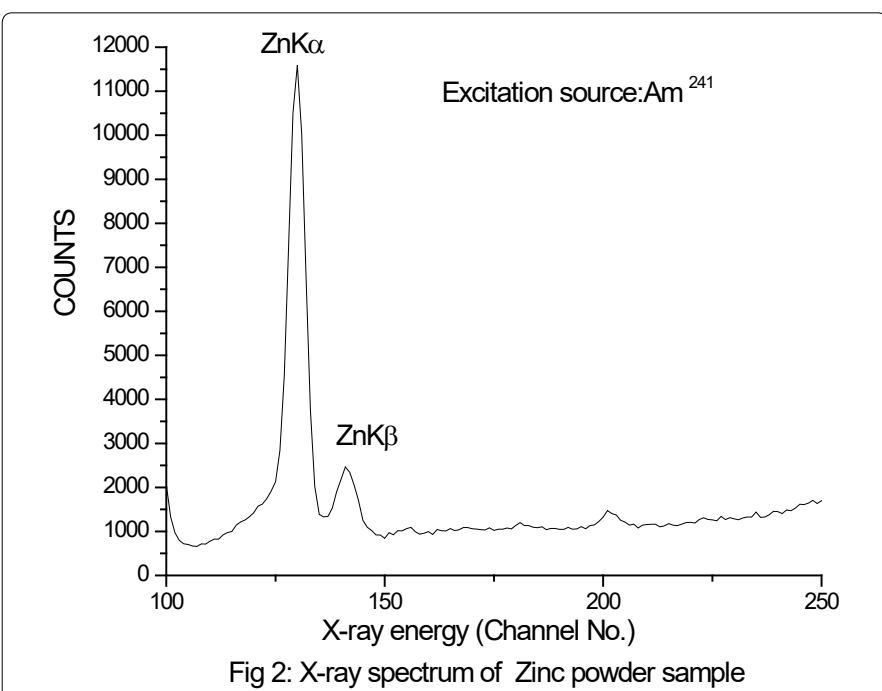

Figure 2. X-ray Spectrum of Zinc powder sample.

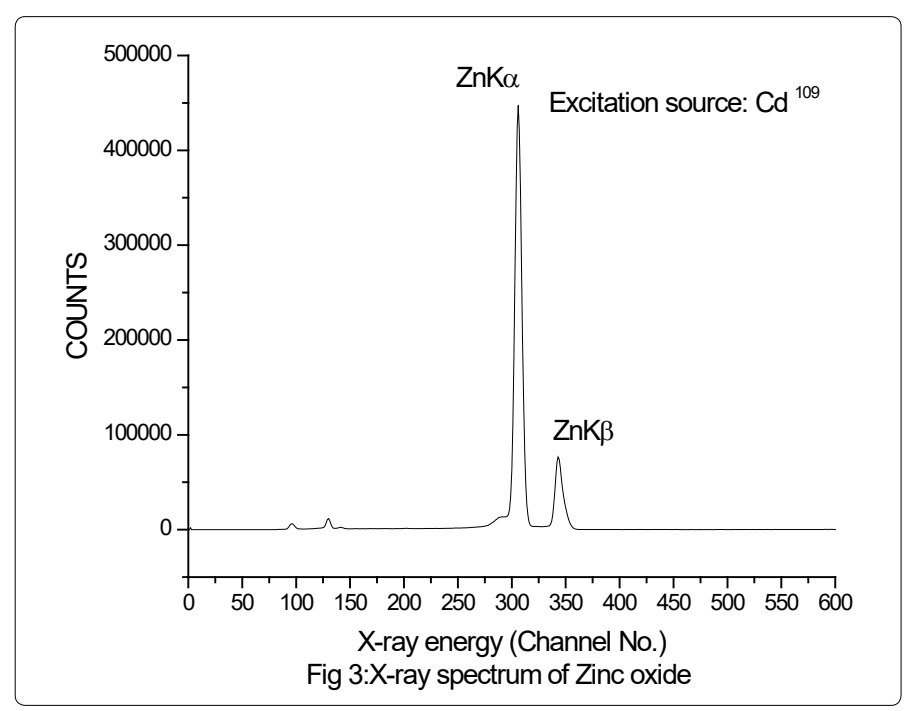

Figure 3. X-ray spectrum of Zinc oxide. 


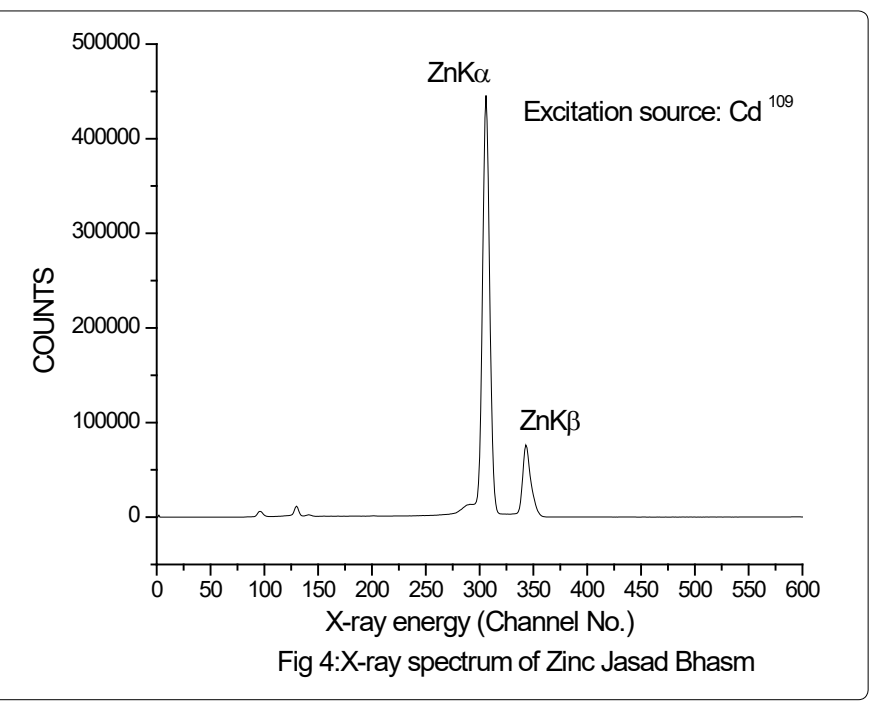

Figure 4. X-ray spectrum of Zinc Jasad Bhasm

\section{References}

1. Vulto AG, De Smet PAGM. Meyler Side effects of drugs. Ed. Dukes, M.N.G 11ed. Elsevier Science Publishers. 1988.

2. Saper RB, et al. Heavy Metal Content of Ayurvedic Herbal Medicine Products. JAMA. 2004; 292(23): 2868-2873. doi: 10.1001/jama.292.23.2868

3. US Environmental Protection Agency. Integrated risk information system.

4. US Pharmacopeial Convention Inc. 2003.

5. Sathe GV. Saritha Sharaangdhar Samhita, 4 Ed. Bombay. 1983.

6. Valkovic K. Trace elements in Biological Systems. 1988.

7. Goel RK, Maiti RN. Effect of Tamrabhasma, an Indian indigenous preparation of copper on rat gastric mucosal resistance. Int.J.Exp.boil. 1994; 32(8): 559-561. 